\title{
Cualidades de la sátira política en Internet: El caso de diario El Mercioco de Ecuador
}

\author{
Marco Sánchez-Peña \\ marcoivansanchez3@gmail.com \\ 100377078@alumnos.uc3m.es \\ Doctorando en Investigación Aplicada a Medios de Comunicación \\ Universidad Carlos III de Madrid \\ Ambato-Ecuador
}

\section{RESUMEN}

En los países con limitaciones a la libertad de expresión, la sátira política se convierte en un vehículo de crítica al poder, convirtiéndose en una forma de periodismo que inquieta a los gobernantes. En este artículo se examinan las cualidades de la sátira política del diario nativo digital de Ecuador, El Mercioco. Tomando como orientación la Teoría General del Humor Verbal, se seleccionaron las noticias satíricas de mayor impacto para someterlas a un análisis crítico del discurso multimodal. También se identificó los mecanismos cómicos que utilizan los redactores del sitio. La fórmula del éxito satírico de El Mercioco podría caracterizarse por la combinación entre texto e ilustración, la utilización de un lenguaje coloquial e incluso vulgar y acudir al doble sentido para crear comicidad. Este medio digital pone en el contexto comunicacional una forma de alimentar la esfera pública a partir de contenidos satírico-humorísticos en redes sociales.

Palabras clave: Sátira Política; Teoría General de Humor Verbal; Análisis multimodal; Mecanismos cómicos; Redes Sociales. 


\title{
Qualities of political satire on the Internet: The case of the newspaper El Mercioco of Ecuador
}

\begin{abstract}
In countries with limitations on freedom of expression, political satire becomes a vehicle for criticism of power, becoming a form of journalism that unsettles those in power. This article examines the qualities of political satire in Ecuador's native digital newspaper, El Mercioco. Taking as a guideline the General Theory of Verbal Humor, the satirical news with the greatest impact on the audience were selected for critical analysis of multimodal discourse. The comic mechanisms used by the site's editors were also identified. The formula for El Mercioco's satirical success could be characterized by the combination of text and illustration, the use of colloquial and even vulgar language and the use of double meaning to create comedy. This digital media puts in the communication context a new way of feeding the public sphere from satiricalhumoristic contents in social networks.
\end{abstract}

Keywords. Political Satire, General Theory of Verbal Humor, Multimodal Analysis, Comic Mechanisms, Social Networks.

Artículo recibido: 05 de Mayo 2021 Aceptado para publicación: 20 de Junio 2021 Correspondencia: marcoivansanchez3@gmail.com Conflictos de Interés: Ninguna que declarar 


\section{INTRODUCCIÓN}

Los estudios en comunicación satírica se enfocan en cómo es utilizado el humor para informar y opinar sobre el devenir noticioso mediante un lenguaje ingenioso. Esta forma de hacer información es parte de la cultura popular de las sociedades y de las prácticas periodísticas de los medios tradicionales.

Con la llegada de internet y las redes sociales la satirización es una alternativa utilizada a nivel global para ejercer crítica al poder mediante el manejo de software utilitario y software social. El resultado son productos comunicacionales con alto nivel de contenido textual potencializados por la imagen ilustrada, lo que abre un espectro interesante para la investigación en los denominados medios nativos digitales.

En 2015 fue cerrado el sitio web y páginas en redes sociales de Crudo Ecuador durante el gobierno de Rafael Correa, lo que evidenció el control de la libertad de expresión en este tipo de sitios y la incomodidad que puede generar para los actores políticos la capacidad de denuncia y crítica al poder de las publicaciones satírico-digitales.

Para determinar cuáles son las cualidades de la sátira política en los medios nativos digitales de Ecuador se analizó las publicaciones de diario El Mercioco. Se aplicó un estudió con enfoque cualitativo, mediante una matriz combinada. Las publicaciones de su página web fueron analizadas con la orientación de la Teoría General del Humor Verbal, anclada a la perspectiva multimodal del discurso y la identificación los mecanismos cómicos utilizados para generar humor con la sátira. Los resultados se explican mediante tres áreas temáticas de las que se desprenden cualidades de la sátira del sitio estudiado.

\section{Libertad de expresión en Ecuador un análisis durante el gobierno de Rafael} Correa

El control a lo que se dice a través de las publicaciones periodísticas inicia con el primer periódico impreso de Ecuador Primicias de la Cultura de Quito creado el 1792. No solo fue el primero en publicarse, también fue el primero en recibir censura desde los colonos españoles por su espíritu combativo y satírico para con el poder de la época y la iglesia.

Mediante el nobel periódico se difundió el espíritu liberal que emergía en América mediante sendos textos críticos y satíricos. Eugenio Espejo su creador y principal 
redactor, fue perseguido y encarcelado, lo que culminó con la eliminación del periódico (Torre Revello, 1940).

Llegado el siglo XX se instaura en Ecuador un marco legal de regulación mediática debido al crecimiento de la radiodifusión que inició en 1929, (Yaguana Romero y Delgado López, 2014) y por el papel importante en la opinión pública de las emisoras radiales. La legislación para la televisión era la misma que para la radio, pero en 2013 con la Ley de Comunicación se establece lineamientos específicos para cada medio, normando su actividad con impacto directo en la forma de emitir sus contenidos. La ley publicada el 25 de junio de 2013 durante el gobierno de Rafael Correa aparece junto con un sistema de control mediático nunca antes visto y que estableció a la comunicación como un bien del pueblo (Asamblea Nacional, 2013. Art. 71).

La libertad de expresión en Ecuador en tiempos de Correa fue amenazada (Montúfar e Ibáñez, 2017), así lo demostró la percepción de los periodistas. El estudio asegura que los principales actores amenazantes desde lo institucional son el gobierno, el poder económico, la SUPERCOM, el CORDICOM, los anunciantes y los dueños y directores de los medios. Estos actores erigieron un ambiente de hostigamiento para los medios tradicionales. Durante esa coyuntura apareció la sátira en internet como una forma contestataria de informar y en cierto modo, incomodar al poder de turno.

Crudo Ecuador fue el primer sitio satírico ecuatoriano que tuvo aceptación desde internet por sus memes y notas cortas en la red social Facebook. Su crítica mordaz fue perseguida hasta ser eliminado su dominio HTTP en 2015 en medio de fuertes críticas a Rafael Correa y su postura recia frente a los contenidos publicados por los medios matriciales y los emergentes nativos digitales (@cdperiodismo, 2015).

\section{MARCO TEÓRICO}

\section{La sátira política en Internet: El Caso de Ecuador}

Aparece la sátira en internet como una forma de poner en lo público temas de importancia que la prensa habitual no puede difundir por las limitantes formales de los géneros habituales como la noticia y por no poder esquivar los cerrojos de la Ley de Comunicación.

En el caso de Ecuador, en Facebook y Twitter han aparecido cuentas que producen contenido satírico-humorístico direccionado a la política de actualidad. Existen sitios web, fanpages y cuentas anónimas que se dedican a la producción de memes y otros que 
publican noticias falsas satíricas. Los de mayor aceptación hasta la fecha del estudio son Crudo Ecuador que registra 709.000 likes en Facebook y 3661 en Twitter, El Mercioco 226.000 likes y 7.666 seguidores, El Uninverso 95.000 likes, (no tiene cuenta Twitter) y El Mercio 44.000 likes y 5.322 seguidores.

De los medios satíricos mencionados los que más actualización muestran en temas y coyuntura informativa política son El Mercioco y Crudo Ecuador. Los que actualmente poseen página web y no solo publican en redes sociales son El Mercio y El Mercioco. Este último demuestra un mayor trabajo informativo y mayor periodicidad. Su web es la más visitada por contener temas de la actualidad política y por hacer uso de una sátira que mezcla lo cotidiano con conocimientos del imaginario popular. También, de forma particular, es el único que, en su diseño de color y tipografía, lo asemeja a uno de los medios tradicionales de mayor influencia en Ecuador, diario El Comercio. Además, tiene incorporado un contador de likes interno que ayuda al registro de reacciones de los visitantes en torno a las notas publicadas, lo que permite tener un censo del impacto de las publicaciones.

\section{Sátira, humor ofake news}

Con la llegada de internet y las redes sociales la satirización es una alternativa utilizada a nivel global para ejercer crítica al poder mediante el manejo de software utilitario y software social. El resultado son productos comunicacionales con alto nivel de contenido textual potencializados por la imagen ilustrada, lo que abre un espectro interesante para la investigación en los denominados nuevos medios nativos digitales.

En Ecuador las primeras imágenes satíricas en internet aparecen alrededor del año 2010 teniendo impacto en 2015 durante el gobierno de Rafael Correa, dónde estos sitios fueron criticados, censurados y cerrados como fue el caso de Crudo Ecuador. Las cuentas que aparecían en redes sociales buscaban mediante un tono irónico y satírico criticar el accionar y hasta el comportamiento de los actores políticos, en ocasiones recreando una situación de la realidad y en otras construyendo un escenario ficticio. La intención en los dos casos es generar humor conectando un hecho, la circunstancia, los protagonistas y con un lenguaje coloquial.

En el contexto de la sátira, internet y las redes sociales, es posible asegurar que el humor y la sátira no desinforman, sino que, promueven el debate político criticando a los agentes informativos tradicionales. Significa que no todas la noticias satíricas son 
enteramente falsas, pues, de acuerdo a (Guimarães, 2019), las fake news se diferencian de las satirical fake news por su propósito de deconstruir los hechos y las noticias para emitir contenidos que pueden alimentar una democracia deliberativa desde los espacios virtuales.

Para Guimarães (2019), el periodo cibernético satírico ha permitido el aparecimiento de narrativas alternativas que se vinculan a los hechos y personas desde otras aristas jugando un papel de desinformación pero con altos contenidos de realidad informativa. La multitud de recursos y fuentes en línea, hacen posible que el proceso de elaboración de la noticia falsa satírica sea activo y tenga amplio rango de difusión en redes sociales. Actualmente "las noticias falsas también son noticias intencionalmente falsas" (Guimarães, 2019: 148), su ánimo es desinformar, pero desde el enfoque satírico, se busca informar con un tono de humor, es invitar a un ejercicio de comprensión más elevado.

El término noticias satíricas Guimarães (2019), lo divide en noticias y sátira para comprenderlo desde dos enfoques y formas distintas poniendo énfasis en la sátira.

"Sátira es el uso del sarcasmo, la ironía, el ridículo para denunciar, exponer o ridiculizar defectos, tonterías, abusos y males de todo tipo en cualquier tipo de medio" (Guimarães, 2019: 149).

Significa que, en términos de comunicación, el receptor/lector, tiene más "responsabilidades" de interpretar el contenido falso dentro de la noticia falsa satírica, y para ello activará su imaginario nutrido por los recursos de conocimiento (Attardo y Raskin, 1991), que el discurso de humor utiliza.

Lo que intenta el enfoque satírico es cuestionar las lógicas de integridad y verdad del periodismo tradicional. Para Marnie Shure quién fue editor gerente del diario satírico The Onion, el mundo está plagado de noticias falsas oficiales y no oficiales; es aquí donde la sátira se ha vuelto necesaria para hacerle pensar a la gente. En 2017 el diario británico The Guardian le dedicó un reportaje a The Onion, en él se aprecia que el tono de humor de las publicaciones aporta al debate político y que separa a la sátira del periodismo falso que intenta engañar (Meade, 2017).

\section{Teoría General del Humor Verbal}

Los estudios sobre el humor abordan la dimensión verbal del chiste. Desde los estudios de ( Attardo y Raskin, 1991; Attardo, 1994; Gurillo, 2014) es posible identificar avances en el análisis estructural del humor en los textos. 
La teoría general del humor verbal (TGHV) planteada en 1991 analizó 7 chistes verbales para identificar sus grados de similitud tomando en cuenta los parámetros de conocimiento detallados en 6 posibles formas. La investigación permite saber que el chiste en su dimensión verbal posee altos niveles informativos que son decodificados por los receptores.

Según el modelo de representación de Attardo y Raskin, (1991), existen 6 recursos de conocimiento que informa la broma o chiste y que estos poseen una jerarquía, sin embargo dicha jerarquía es una propuesta discutible, pero propone parámetros claros. Los 6 recursos propuestos ayudan a identificar con precisión los elementos que hacen que un texto sea humorístico. Son: el lenguaje, la estrategia narrativa, el objeto del chiste, la situación, los mecanismos lógicos y la oposición de guiones.

Si se observa desde una perspectiva jerarquizada es posible decir que la oposición de guiones inicia el camino hacia finalmente exponer el chiste con el uso del lenguaje, pero este orden puede ser entendido de forma libre pues la digitalización del mensaje satírico, que es lo que atiende este estudio, no posee un orden determinado. Sus características estéticas varían de acuerdo al uso de las herramientas digitales, la perspectiva de visualización y la decisión en el uso del recurso de conocimiento primario.

\section{El análisis multimodal: Una propuesta para analizar la sátira en Internet}

En el pasado ya existían textos multimodales como los periódicos o los textos para el cine. La multimodalidad se daba gracias a los procesos de edición que son una forma de crear significados de forma grupal. Todas las partes eran integradas de tal forma que se generaba un producto comunicacional jerarquizado por los mismos creadores. En la actualidad estos procesos de creación pueden ser ejecutados por una misma persona, sin que ello represente pérdida en la elaboración de significados. Esta individualidad en la elaboración de productos multimodales sucede gracias a la digitalización y la posterior instrumentalización que existe a gran escala (Debasa, 2018).

La edad digitalizada ha permitido que "todos los medios sean lo mismo, en cierto nivel de representación" (Kress y van Leeuwen, 2001: 2), y la manipulación de los recursos tecnológicos hace posible que el creador de contenido pueda decidir entre el texto y los recursos audiovisuales. Es por eso que se puede asegurar que todo texto o publicación en internet es multimodal. 
Hoy los medios de comunicación poseen numerosos recursos modales para la elaboración de mensajes, la palabra hablada o escrita, la imagen estática y en movimiento, música, objetos en 3D, bandas sonoras de acción u otras (Kress, 2003), que amplían el espectro de significación y pueden ser utilizados para potenciar un mensaje con estilo particular. En este estudio se pretende ir más allá de la articulación entre significado y significante y abordar las publicaciones satíricas como construcciones de sentido en múltiples articulaciones. Reconocer que las publicaciones en internet contienen cierto contenido humorístico tiende a ser una muestra de retórica extrema que se amplía gracias a la propagación que permite internet y las redes sociales digitales (Hakoköngäs, Halmesvaara, y Sakki, 2020).

Los estudios multimodales buscan analizar las conexiones que existen entre los recursos utilizados en la elaboración de los mensajes. En el caso de la sátira política de $E l$ Mercioco se asume que es "no solamente una tecnología unificada y unificante, sino una semiótica unificada y unificante" (Kress y van Leeuwen, 2001: 2). Se refiere a que los elementos de una composición visual pueden estar desconectados, pero semióticamente tienen una conexión. Esta conexión se da a nivel de formas visuales que hace posible la interpretación de significados individuales por cada elemento y una significación conjunta por la unificación de los elementos en una publicación digital.

La perspectiva multimodal no se limita al estudio del contenido fijo como lo es la escritura, sino que ve otros elementos de representación en la comunicación. Es una ampliación del estudio del lenguaje al estudio combinado con otros recursos (O’halloran, 2016). Para responder al desafío de estudiar una combinación de elementos. Kress y van Leeuwen (2001), plantean un modelo de estratos que está compuesto por Discurso, Diseño, Producción y Distribución, que Williamson (2005), aseguran son una forma de insistir en los recursos semióticos de los que dispone el emisor de un mensaje.

\section{Mecanismos cómicos}

Los mecanismos cómicos operan cómo vínculo entre la producción redaccional, la cultura popular y el contexto informativo. Si bien Bordería, Martínez, y Gómez, (2010) los identifican desde la institución televisiva humorística, se los puede asociar con la producción de sátira en internet por su vínculo con el multimedia. Estos mecanismos permiten acercarse con precisión al contenido intelectivo de un chiste o una broma, pues 
asocia una idea con varias características como una emoción, un sonido, el color u un contenido audiovisual. Puede parecer que es un esquema funcionalista, pero permite generar categorías analíticas ante la creciente variedad de contenidos humorísticos. Los mecanismos identificados en (Bordería, Martínez, y Gómez 2010) son la exageración, la inversión, la impropiedad, la sustitución, el doble significado, la expresión limitada y la repetición.

\section{ESTRATEGIAS METODOLÓGICAS O MATERIALES Y MÉTODOS}

Se planteó un método analítico-explicativo en tres fases: La primera se encargó del análisis desde la teoría general del humor de (Attardo y Raskin, 1991) tomando en consideración los recursos de conocimiento que plantean los autores y aplicándolos a los textos noticiosos satíricos de El Mercioco.

La segunda fase estuvo enfocada en identificar y explicar los elementos del discurso multimodal de las publicaciones según lo planteado por (Kress y van Leeuwen, 2001) en lo que a su análisis por estratos de 4 elementos se refiere. Además de las orientaciones analíticas planteadas por (Machin, 2007).

Finamente en la tercera fase, de acuerdo a lo planteado por Bordería et al., (2010), se planteó la identificación y descripción de los mecanismos cómicos utilizados en las noticias satíricas de política en el diario El Mercioco.

Los aportes teóricos fueron plasmados en una ficha combinada de análisis que se aplicó a las publicaciones. Las noticias satíricas fueron seleccionadas a partir de la lógica de impacto por el número de likes que se registra en el contador de la página web del medio. Con ello fue posible identificar las cualidades de la sátira publicada en cada nota.

Para el estudio fue seleccionado diario El Mercioco debido a que publica información con mayor frecuencia y utiliza más recursos de redacción e imagen, lo que lo asemeja a un medio tradicional.

Para determinar las publicaciones a ser analizadas se aplicó un muestreo estratégico tomando las primeras 25 con más impacto en número de likes y que fue hasta donde se presentó el punto de saturación. En general, todas las publicaciones poseen características de similitud, cómo el uso de imagen, texto, misma tipografía y color; sin registrarse mayores cambios durante los años de publicación, lo que asegura la representatividad. 
Fueron registradas manualmente la totalidad de las publicaciones de la sección noticias del sitio web http://elmercioco.com/ sumando 4159 entre 2010 y 2019, siendo la fecha de corte el 31 de marzo de 2020.

El total de publicaciones que se enfocan al ámbito del humor político a nivel Ecuador y otros países suman 1395. Una vez ordenadas por número de likes, la nota con mayores reacciones tiene 73000 likes. A partir de ésta se aplicó la ficha de análisis combinada.

\section{RESULTADOS Y DISCUSIÓN}

Desde los recursos de conocimiento de la Teoría General del Humor Verbal se distinguió que el lenguaje coloquial es el más utilizado en la redacción de las noticias satíricas y en ocasiones se acude al lenguaje vulgar. Se determinó que el uso de ciertos vulgarismos y términos propios del léxico ecuatoriano son utilizados para temas dónde se critica al poder y se hace chistes más personalizantes. También se distinguió el uso de palabras provenientes del quechua y su derivación en quichuismos para satirizar personajes y circunstancias dónde el regionalismo existente en Ecuador toma protagonismo. En menos número aparecen palabras del inglés para ilustrar el contexto satírico del chiste.

En lo que respecta a las estrategias narrativas en el texto se describe su uso en las noticias analizadas en la figura 1 y en lo que respecta a objetos del chiste, situación, mecanismos lógicos y oposición de guiones, son ubicados dentro de tres grupos de temas generales fruto del análisis cualitativo de las publicaciones: Crítica en el chiste, Chistes sobre la capacidad de gobernar y Chistes personalizantes o generalistas.

Figura 1: Estrategias narrativas.

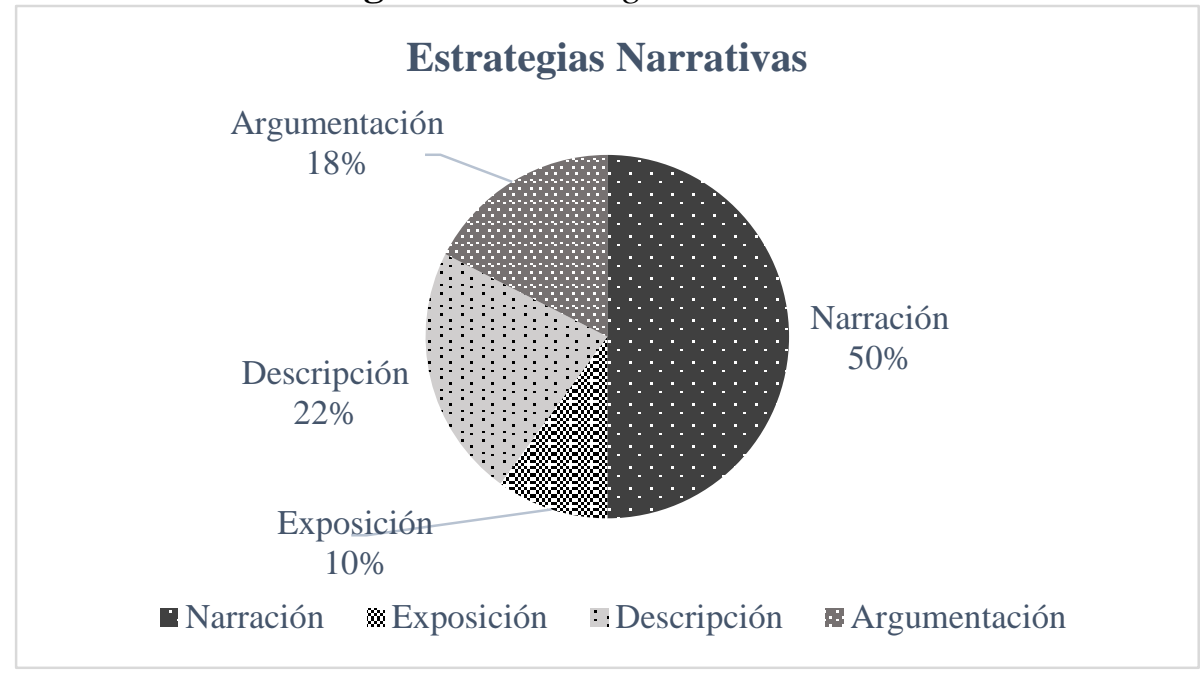

Fuente: Elaboración propia a partir de Ficha de análisis combinada. 
De acuerdo a la multimodalidad, las noticias satíricas de El Mercioco poseen elementos de significación propios del ecosistema virtual por la existencia de múltiples recursos en la creación. La potencia de sus notas está en la creación de situaciones ficticias a partir de realidades locales. De ahí que el periodismo satírico en el caso de este sitio ecuatoriano, está directamente ligado a situaciones reales haciendo que parezcan verdad por la eficiente relación que existe entre los recursos textuales de la redacción y los elementos visuales.

Los chistes pasan por un proceso de diseño que utiliza las posibilidades del software de edición para elaborar ilustraciones que son una hibridación entre fotografía, imagen y texto.

Cómo las notas están en un soporte digital la redacción acude a utilizar nombres de forma precisa para que estos sean fácilmente ubicados en los buscadores como una forma de insertar el producto en la variedad de sitios existentes en internet.

En su discurso las notas apuntan fuertemente a desarrollar el qué, es decir se preocupa en la creación del hecho en el chiste. El quién aparece como una forma de hacer más directo el mensaje. Algunos chistes se apoyan en el dónde para ubicar, con un ánimo regionalista la nota publicada. El cuándo y el cómo son elementos de argumentación que no siempre es utilizada en la redacción.

Figura 2: Elementos del discurso.

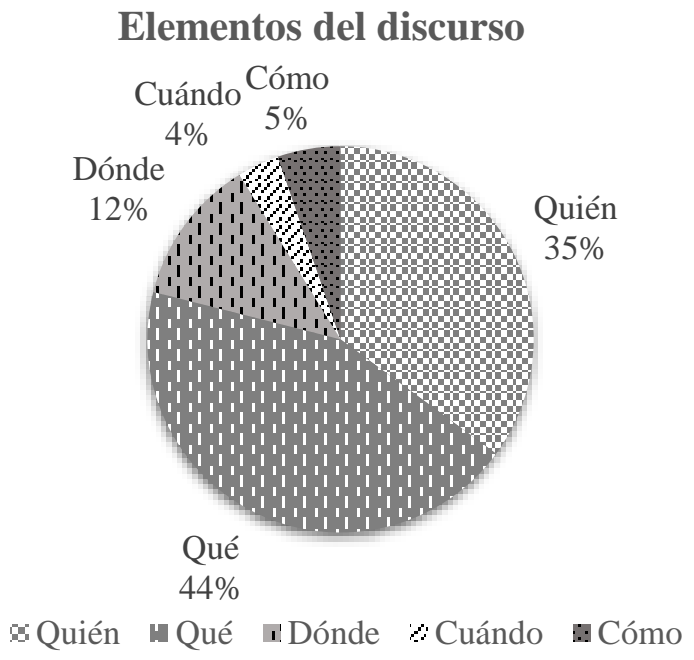

Fuente: Elaboración propia a partir de Ficha de análisis combinada. 
El diseño de la noticia satírica en la era de internet se potencia gracias a las posibilidades de hibridación de imagen y texto en formas que incrementan el impacto de la noticia. Este elemento es el responsable de crear una verdad a partir de los recursos de conocimiento. Las ilustraciones de imágenes en ocasiones combinadas con texto pueden contar el chiste y generar humor de forma independiente. Se pudo notar que se ilustra a partir de fotografías de los objetos del chiste y son insertados otros elementos de imagen como caricaturas con el fin de representar el chiste que se narra en el texto. Significa que primero se crea el texto y luego la imagen que lo representa.

Figura 3: Elemento multimodal diseño.

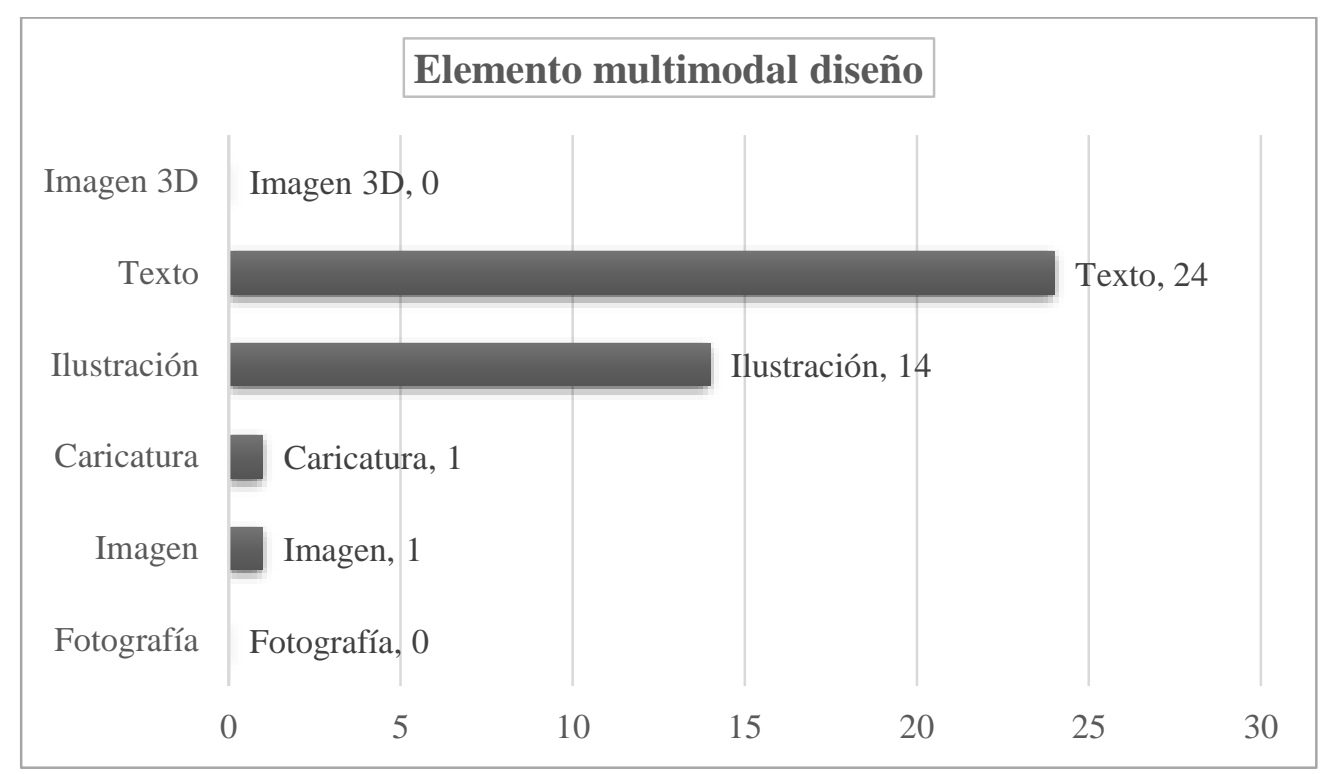

Fuente: Elaboración propia a partir de Ficha de análisis combinada.

La multimodalidad desde la producción de las notas satíricas identificó que cada una tiene un carácter individual, es decir se publica una nota por tema creado y no existe seguimiento de historia como lo haría el periodismo informativo tradicional. Cada nota tiene una producción diferenciada. Además, los chistes crean circunstancias que son complejas de representar con imágenes de ahí que en la mayoría de los casos estudiados el texto es el único recurso de producción.

El Mercioco al ser un medio nativo digital utiliza internet como su medio de distribución y por ende esa es su forma de ingresar en lo social. También aprovecha las redes sociales para ganar impacto. Cabe mencionar que no todas las notas publicadas en su sitio web aparecen en Facebook o Twitter, por eso se analizó su página web apoyado en los factores que detallan Salaverría y Sancho, (2007). 
Los elementos de distribución más utilizados en las publicaciones son el multimedia y el metainformativo. Lo multimedia es notorio en la utilización de imágenes ilustradas y la inserción de video, el video, por ende, desprende también el uso del multiplataforma. El uso del lenguaje metainformativo apela al uso de nombres propios fácilmente localizables en los buscadores de la red, lo que aporta a la ubicación de la nota en la web.

Figura 4: Elemento multimodal producción.

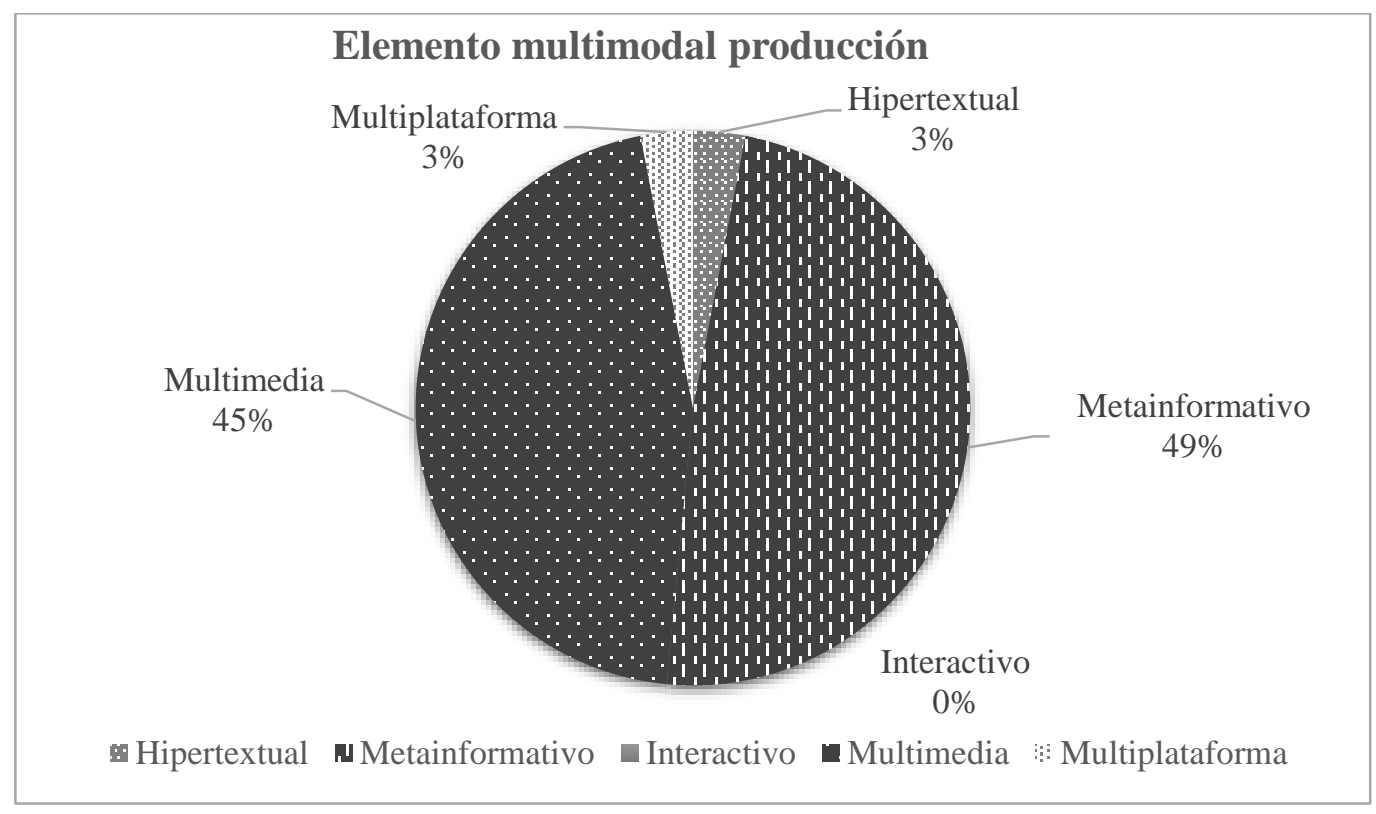

Fuente: Elaboración propia a partir de Ficha de análisis combinada.

Desde los mecanismos cómicos se distinguió que la mayoría de los chistes acuden al doble significado para generar humor, es decir al contenido latente (Freud, 2011, [1899]) del mensaje que se produce. En la redacción de las notas existe un contenido manifiesto que se lo puede notar en las imágenes que las acompañan, pero lo que está detrás se lo entiende por el contexto del chiste e incluso por términos polisémicos que incentivan diferentes interpretaciones.

También es utilizada la exageración como una forma de hacer que el hecho ficticio gane en credibilidad por la tendencia a hiperbolizar algunas palabras. La impropiedad es utilizada como una forma de dar vida existencial a una persona u objeto permitiendo que se cree una realidad ficticia creíble. La sustitución, repetición y la expresión limitada no son recurrentes debido a que siembre se apunta a un objeto en los chistes y a la redacción de las notas con un tono casi periodístico. 
Los mecanismos cómicos estructuran dos tonos que denotan las intenciones en la creación de las notas, el sarcasmo o doble significado y dirigir el chiste a la personalidad del objeto.

El sarcasmo en el doble significado implica que los chistes tienen significados escondidos detrás del significado primario del contenido manifiesto. Esa estructura imaginaria solo puede ser decodificada por conocimientos que están en la mente del que lee una nota satírica. El doble significado rompe el silencio de los temas mediante la capacidad intelectiva de las audiencias. El sarcasmo en el doble sentido es una forma de ejercer crítica. No siempre aparece expuesta evidentemente, aparece como una invitación a pensar en un significado secundario que es evidente en el imaginario social más no en el texto o en la imagen ilustrada.

$\mathrm{Al}$ dirigir el chiste a la personalidad de los objetos políticos significa que la producción de sátira tiene un nivel alto de conocimiento del contexto que rodea a ese objeto. Hay un control de la coyuntura y de hechos historiográficos para con ello crear un chiste que construya circunstancias que son cercanas al imaginario social colectivo. Al concentrarse este estudio en la sátira política fue posible identificar que los chistes direccionados a las personas buscan molestar y generar una opinión divergente en las personas, es por ello que se acude al humor como una forma socialmente aceptada de crear molestia y controversia.

Figura 5: Mecanismos cómicos.

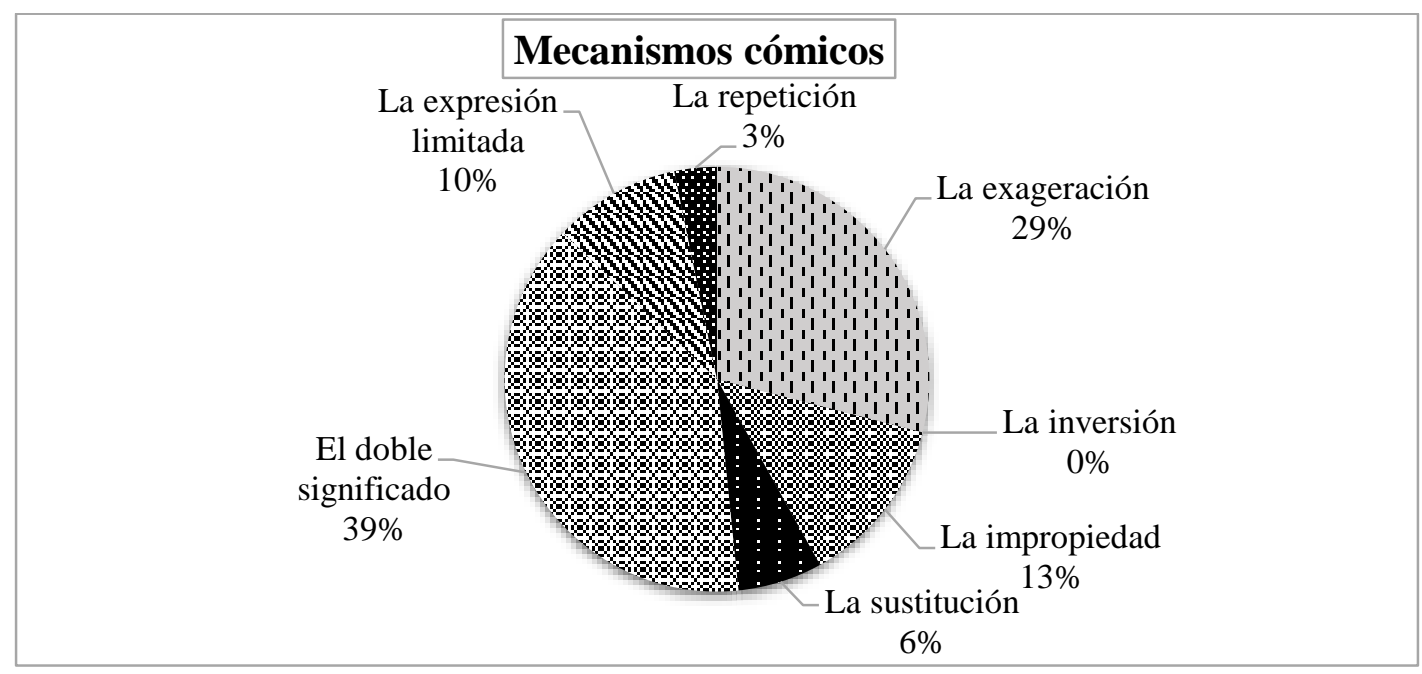

Fuente: Elaboración propia a partir de Ficha de análisis combinada. 


\section{CONCLUSIÓN O CONSIDERACIONES FINALES}

Internet le ha otorgado un nuevo escenario a la sátira política y su producción es una condensación de recursos. El incremento de estos sitios en redes demuestra que se está acudiendo a este tipo de discurso como vehículo de crítica contra el poder.

Una de las cualidades de la sátira política en El Mercioco es la forma hiperpersonalizante de hacer crítica a quienes ostentan el poder y tienen visibilidad política. Esta es una nueva forma de comunicación que puede trascender de la realidad virtual a la realidad real.

Desde la Teoría General del Humor Verbal (TGHV) se pudo comprobar que una de las cualidades de la sátira en El Mercioco es la creación de situaciones ficticias utilizando principalmente la narración con un lenguaje coloquial congruente. En las notas existe un alto nivel de conocimiento de la realidad política en la producción de notas satíricas.

Se determinó que la multimodalidad de las notas satíricas es más fuerte en el recurso texto y que existe una dimensión modal que sólo es posible por la mediación del software para la edición de imágenes, la ilustración. La era de internet y el aparecimiento del software aporta al diseño, producción y distribución de este tipo de contenidos.

En los discursos satíricos mayormente existe un discurso oculto por la utilización del doble sentido. Los chistes con doble sentido son sarcásticos lo que significa que se opta por hacer una crítica indirecta al objeto mediante la creación de una situación secundaria en torno al chiste.

\section{LISTA DE REFERENCIAS}

@cdperiodismo. (2015). "CIDH se pronunció por cierre de web crítica en Ecuador". Clases de periodismo.

2015. https://www.clasesdeperiodismo.com/2015/02/25/cidh-se-pronuncio-por-cierrede-web-critica-en-ecuador/.

Attardo, Salvatore. (1994). Linguistic Theories of Humor. Berlin: Mouton de Gruyter.

Attardo, Salvatore, y Victor Raskin. (1991). "Script theory revis(it)ed: Joke similarity and joke representation model". Humor 4 (3-4): 293-348. https://doi.org/10.1515/humr.1991.4.3-4.293.

Bordería, Enrique, Francesc Martínez, y Josep Gómez. (2010). La risa periodística: Teoría, metodología e investigación en comunicación satírica. Primera. 
Valencia: Tirant lo Blanch.

Debasa, Felipe. (2018). "Nuevos retos sociales en la IV Revolución Industrial". TELOS 110: 126-31. https://telos.fundaciontelefonica.com/telos-109-regulacion-felipedebasa-nuevos-retos-sociales-en-la-iv-revolucion-industrial/.

Ecuador, Asamblea Nacional. (2013). Ley orgánica de Comunicación. Quito: Registro Oficial.

Freud, Sigmund. (2011). La interpretación de los sueños. Barcelona: Alianza Editorial. Guimarães, Paulo João. (2019). "Amenazas al Ciberperiodismo". En Satirical Fake News, editado por Ana Isabel Reis, Pedro Jerónimo, Fernando Zamith, y Helder Bastos, 396. Porto: Universidad de Porto-Facultad de Letras. https://repositorioaberto.up.pt/handle/10216/119348.

Hakoköngäs, Eemeli, Otto Halmesvaara, y Inari Sakki. (2020). "Persuasion Through Bitter Humor: Multimodal Discourse Analysis of Rhetoric in Internet Memes of Two Far-Right Groups in Finland". Social Media + Society 6 (2): 1-11. https://doi.org/10.1177/2056305120921575.

Kress, Gunther. (2003). Literacy in the New Media Age. Primera. London: Routledge. https://doi.org/10.1353/lan.2006.0242.

Kress, Gunther, y Theo van Leeuwen. (2001). Multimodal Discourse: The Modes and Media of Contemporary Communication. First. London: Arnold Publication.

Machin, David. (2007). Introduction to Multimodal Analysis. First. Berna: Bloomsbury Academic.

Meade, Amanda. (2017). "The Onion en la era de Trump: «Lo que hacemos se vuelve esencial cuando sus objetivos son tan payasos»". The Guardian, 2017. https://www.theguardian.com/culture/2017/aug/28/the-onion-in-the-age-oftrump-what-we-do-becomes-essential-when-its-targets-are-this-clownish.

Montúfar, Fernando Checa, y Daniel Barredo Ibáñez. (2017). "Medios públicos y libertad de expresión en la percepción de los periodistas: Un estudio comparativo (2008-2015)". Revista Latinoamericana de Ciencias de la Comunicación https://www.alaic.org/revista/index.php/alaic/article/view/761.

O’halloran, Kay L. (2016). "Análisis del discurso multimodal". Revista Latinoamericana de Estudios del Discurso $12 \quad$ (1): 75. 
https://doi.org/10.35956/v.12.n1.2012.p.75-97.

Ruiz Gurillo, Leonor. (2014). "Infiriendo El Humor. Un modelo de análisis para el español". Círculo de Lingüística Aplicada a la Comunicación 59: 148-62. https://doi.org/dx.doi.org/10.5209/rev_CLAC.2014.v59.46712.

Torre Revello, José. (1940). El Libro, La Imprenta y El periodismo en América durante la dominación española. Primera. Buenos Aires: Talleres S.A. Casa Jacobo.

Williamson, Rodney. (2005). "¿A qué Le Llamamos Discurso en una perspectiva Multimodal? Los Desafíos de una nueva Semiótica.". Aled 6: 70-89. https://es.scribd.com/document/409984020/A-que-le-llamamos-DiscursoMultimodal.

Yaguana Romero, Hernán, y Washington Delgado López. (2014). 85 años de la radiodifusión en Ecuador. Primera. Quito: Quipus. 